\title{
An unusual case of labial fusion in a post pubertal girl
}

\author{
Kinnari Amin*, Bhamini Kadikar, Heena Rajput, Krupa Patel, Nilesh Shah
}

Department of Obstetrics and Gynaecology, Nootan Medical College and Research Centre, Visnagar, Gujarat, India

Received: 22 April 2021

Accepted: 12 May 2021

\author{
*Correspondence: \\ Dr. Kinnari Amin, \\ E-mail: kinnari.amin.127@gmail.com
}

Copyright: () the author(s), publisher and licensee Medip Academy. This is an open-access article distributed under the terms of the Creative Commons Attribution Non-Commercial License, which permits unrestricted non-commercial use, distribution, and reproduction in any medium, provided the original work is properly cited.

\begin{abstract}
Labial fusion is defined as either partial or complete adherence of the labia minora. It is also known as vulvar fusion, labial adhesion, labial agglutination or synechia of the vulva. This condition is common in pre-pubertal girls when estrogen levels are low and commonly resolves spontaneously post-puberty. This condition is usually asymptomatic and can be treated with topical application of estrogen or betamethasone cream or by manual or surgical separation of adhesions. We present a case of labial fusion in post pubertal girl which was managed surgically.
\end{abstract}

Keywords: Labial adhesion, Labial fusion, Labial agglutination, Synechia vulvae

\section{INTRODUCTION}

Labial fusion is the condition in which the lips of labia minora around the opening of vagina become fused together or get covered with a fleshy membrane. The membrane usually completely covers the vaginal opening, leaving a very small gap at the front through which urine and menstrual blood passes. Labial fusion commonly occurs in $0.6 \%-5 \%$ of prepubertal girls, with a peak incidence of around 3 percent in the second year of life. ${ }^{1,2}$ However, it rarely occurs in adults; very few cases have been reported in the literature with predominant occurrence in postmenopausal women rather than in reproductive age group women. ${ }^{3-5}$ Labial fusion may be partial, involving upper or lower labia, or complete. ${ }^{2}$

\section{CASE REPORT}

15 years old, 9th standard student, came to Gynecology outpatient department with complaint of menorrhagia since 2 months. She attended menarchae at 13 years of age. Her menstrual cycles were regular with increased menstrual flow. It was of normal duration with occasional dysmenorrhea. Her bladder and bowel habits were normal. There was no history suggestive of any local perineal injury, infection or application of any substance. There was no history of any sexual abuse or complaints of irritation or allergic rash over perineum in the past. There was no history of any significant major medical, surgical or dermatological disorder. No history suggestive of any congenital anomaly at the time of birth. General and systemic examination was normal. Her secondary sexual characters were well developed and vitals were stable. On abdominal examination, her abdomen was soft and non tender. Local examination revealed normal labia majora, while labia minora were fused in the midline with a small pinpoint opening of around $0.5 \mathrm{~mm}$ in the centre. (Figure 1) This was the common opening for both urination and menstruation. Urethral orifice was not visualized at normal anatomical position. No visible scars on the perineum. On per rectal examination, uterus was normal in size, anteverted, firm, mobile. Bilateral fornices were free and non tender.

All routine investigations necessary for surgery were done and found to be normal. Ultrasound showed normal size, anteverted uterus with normal bilateral adnexa. Ultrasound of abdomen also suggested normal findings. MRI abdomen with pelvis was done to rule out any urogenital anomaly. On MRI, both urethral and vaginal tracks were 
seen separately with close proximity of lower most parts of urethra and vagina near it's opening suggestive of low variety of urogenital sinus abnormality. No evidence of utero-vesicle or vesico-vaginal fistula. Decision for reconstruction of labia minora was taken. Opinion of urosurgeon was taken preoperatively. Procedure was done under saddle anaesthesia. $0.5 \mathrm{~mm}$ size hegar's dilator was passed through the common opening to identify the tract. Then artery forcep was passed through the opening and fused tissue was dissected with sharp dissection in downward direction and in upward direction towards the urethral meatus. (Figure 2)

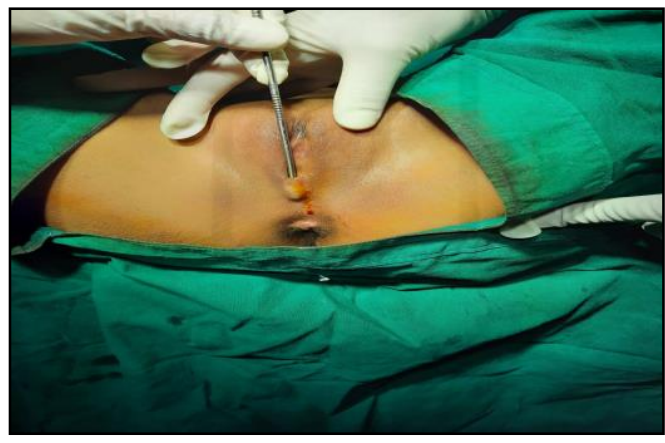

Figure 1: Preoperative picture showing fused labia with single common opening for both micturition and menstruation through which a Hegar's dilator is passed.

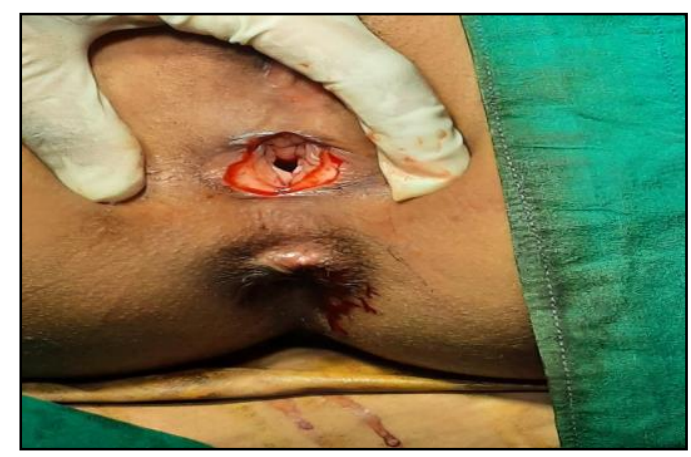

Figure 2: After surgical excision of fused tissue, vagina can be seen.

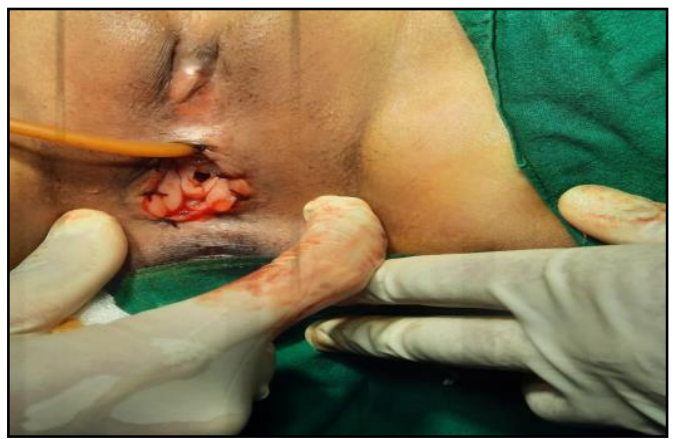

Figure 3: Foley's catheter through the urethra.
Vagina with normal rugosities and normal healthy cervix was visualized. Raw edges of incision were approximated with interrupted sutures using delayed absorbable suture material. Her post operative course was uneventful. Urinary catheter was removed on next day. Patient passed urine normally. Antibiotic ointment was given for local application. On follow up, patient was in menses with no menstrual complaint. (Figure 4)

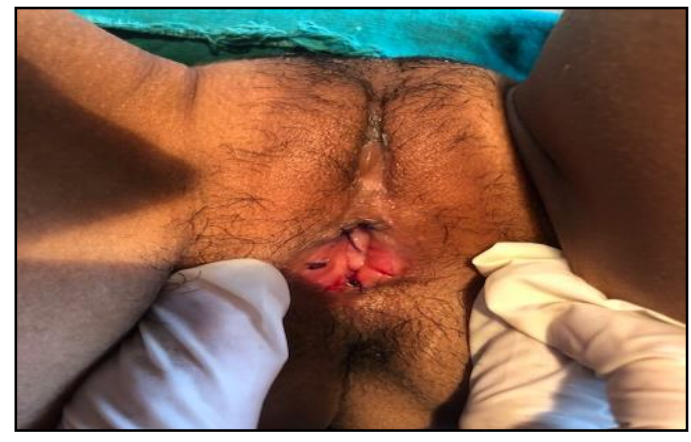

Figure 4: Post operative picture on 15th day showing healed dissected tissue.

\section{DISCUSSION}

Labial adhesion occurs when the labia minora adhere together resulting in narrowing of vaginal introitus. It is commonly seen in prepubertal girls and postmenopausal women; however, it is rarely seen in reproductive age group women. It gives an impression of absent vagina. It is often an acquired condition, but it can also occur as a congenital anomaly, usually accompanied by other genitourinary abnormalities. It can be asymptomatic or may lead to urinary symptoms such as urinary retention, pain or altered urinary stream, urinary tract infection. The condition is usually painless. Sometime there may be soreness of vulva after urination or dribbling of urine after going to the toilet. Women of the reproductive age group mostly presents with difficulty in engaging in sexual activity. Patient may not be able to pass urine in severe cases.

Though the exact cause is unknown, it is suspected that labial adhesions are caused by irritation and inflammation of external genitals. These irritants could be urine, faeces, bubble bath, perfumed soaps, poor hygiene leading to inflammatory conditions such as vulvitis, pinworm infestation, atopic dermatitis, cicatrisation following trauma, delivery or sexual abuse or condition leading to hypoestrogenism. 6 It has been postulated that low levels of estrogen

is a predisposing factor for labial adhesion in prepubertal girls and postmenopausal women. ${ }^{6}$

Usually, the labia start to fuse at the posterior fourchette and work up towards the clitoris. Low levels of estrogen are thought to be responsible for development of such adhesions. This condition usually resolves spontaneously 
at puberty in upto $80 \%$ of girls as the effect of estrogen changes the cells that line the genitals.

The medical management of labial fusion for young girls is application of topical estrogen cream on the labia minora. Conjugated estrogen cream or estradiol vaginal cream $(0.01 \%)$ can be applied to the adhesions 1-2 times daily for several weeks until the adhesion resolves. ${ }^{7}$ Adverse systemic effects of estrogen application are rare which include local irritations, vulvar pigmentation and breast enlargement.

An alternative line of management is topical application of $0.05 \%$ betamethasone cream twice daily for $4-6$ weeks. ${ }^{8} \mathrm{~A}$ retrospective study comparing medical treatment with estrogen cream alone, betamethasone cream alone or combination of both for 2 to 4 weeks showed no significant differences among the study group. ${ }^{9}$

Surgical adhesiolysis is required in 5 to $10 \%$ of cases. ${ }^{10,11}$ Irrespective of the mode of treatment, recurrence rate is $40 \% .{ }^{12}$ Surgical management maybe required if adhesions are dense or if patient is not responding to medical line of management. After surgical management, antibiotic cream is applied for few days to prevent recurrence of adhesions. Adhesions which recur after surgery are usually denser and are less likely to resolve with medical line of management. Surgical management with use of rotational skin flaps or amniotic membrane is required in such cases. ${ }^{13,14}$ According to comparative study conducted by Mirzaman, surgical separation techniques are superior to manual separation techniques to reduce the chances of recurrence. ${ }^{15}$

\section{CONCLUSION}

This is a rare case of labial fusion in post pubertal girl without any identifiable cause which required surgical management.

Funding: No funding sources Conflict of interest: None declared

Ethical approval: Not required

\section{REFERENCES}

1. Mayoglou L, Dulabon L, Martin-Alguacil N, Pfaff D, Schober J. Success of treatment modalities for labial fusion: A retrospective evaluation of topical and surgical treatments. J Pediatr Adolesc Gynecol. 2009;22: 247-50.
2. Bacon JL, Romano ME, Quint EH. Clinical recommendation: Labial adhesions. J Pediatr Adolesc Gynecol. 2015;28:405.

3. Tsujita Y, Asakuma J, Kanbara T, Yoshii T, Azuma $\mathrm{R}$, et al. A case of labial adhesion in a reproductive woman. Europe PMC. 2010;56:463-5.

4. Ozekinc M, Yucel S, Sanhal C, Erman Akar M. Labial fusion causing coital and voiding difficulty in a young woman. Adv Sexual Med. 2013;3:11-3.

5. Al-Hubaishi F, Al-Najjar F, Al-Medfa AS. A Case Report on an Asymptomatic Labial Fusion in a Woman of Reproductive Age. Gynecol Obstet Case Rep. 2018;4(1):60.

6. Ghose S, Pallavee P, Begum J, John LB, Samal SK. Labial Adhesion in Adult Female. J South Asian Feder Obst Gynae. 2015;7(3):207-9.

7. Goldman RD. Child health update: estrogen cream for labial adhesion in girls. Can Fam Physician. 2013;59(1):37-38.

8. Myers JB, Sorensen CM, Wisner BP, Furness PD, 3rd, Passamaneck M, Koyle MA. Betamethasone cream for the treatment of pre-pubertal labial adhesions. J Pediatr Adolesc Gynecol. 2006;19(6):407-11.

9. Eroglu E, Yip M, Oktar T, Kayiran SM, Mocan H. How should we treat prepubertal labial adhesions? Retrospective comparison of topical treatments: estrogen only, betamethasone only, and combination estrogen and betamethasone. J Pediatr Adolesc Gynecol. 2011;24(6):389-91.

10. Muran D. Treatment of prepubertal girl with labial adhesion. J Pediatr Adolesc Gynaecol. 1999;12(2):6770 .

11. Bhave NV, Shah PK, Chaudhari H. An unusual case of labial fusion. Int $\mathrm{J}$ Reprod Contracept Obstet Gynecol. 2016;5:572-5.

12. Al Jurayyan NAM. Labial agglutination (Adhesion) in prepubertal girls. What a primary care physician should know? Primary Health Care. 2012;2(5):128.

13. Lin YH, Hwang JL, Huang LW, Chou CT. Amniotic membrane grafting to treat refractory labial adhesions postpartum - a case report. The Journal of Reproductive Medicine. 2002;47:235-7.

14. Johnson N, Lilford RJ, Sharpe D. A new surgical technique to treat refractory labial fusion in the elderly. American Journal of Obstetrics and Gynecology. 1989;161:289-90.

15. Mirzaman H. Pre-pubertal labial adhesion surgery: The first study to compare manual or surgical separation. Ann Med Res. 2019;26(6):991-4.

Cite this article as: Amin K, Kadikar B, Rajput H, Patel K, Shah N. An unusual case of labial fusion in a post pubertal girl. Int J Reprod Contracept Obstet Gynecol 2021;10:2890-2. 